\title{
INCREASED PRODUCTION ON DAIRY FARMS
}

By P. W. SMALLFIELD, Director, Extension Division, Department of Agriculture, Wellington.

Recently officers of the Extension Division of the. Department of Agriculture carried out a county by county survey of the Dominion to define what increases in carrying capacity were both possible and probable by 1975 , and what the ultimate potentiai carrying capacity was likely to be. They based their estimates on past trends in livestock numbers on each soil type and probable developments in farm management methods and their summarised conclusions indicate that in 1975 our most likely increase would be about 27 per cent. but that it would be possible to increase by 45 per cent. and that our ultimate potential increase might be 67 per cent. This estimate covers all land in the Dominion and, of course, includes large areas of pastoral land which with our present knowledge and economic conditions is not improvable. Some of you may think these'estimates too high; others will certainly, think them too low. As grassland workers I think we should analyse the basic conceptions underlying these estimates and discuss methods by which we may attain as rapid an increase as possible. For I may mention that this forecasting work was undertaken in view of the fact that the population of the Dominion is likely to be $2,750,000$ by 1975 and if the productive capacity of our farming lands is not increased at a rate comparable with our population growth our wealth and well-being are likely to suffer.

This forecast was, as I said, based on past trends and probable and possible future advancements in grassland farming methods. Let us then look at the trends in feed production on dairy farms over the past 30 years, discuss our present management methods and possible future developments.

Thirty years ago our dairying grasslands were, in the main, worked on a long-rotation system and fodder crops were important in the supplementary feeding 
system, In general, owing to the lack of perennial ryegrass in the sward, pastures gave poor winter and spring production and hay and roots were the mainstay of winter feeding. From then till now the trend in increased carrying capacity has followed fairly closely the development of perennial ryegrass-white clover pastures. Most of our.ideas of possible trends in dairy cow numbers and production are based on the conception of full production and utilization of those pastures.

The essentials of production and utilisation of perennial ryegrass-white clover pastures áre bound up with the habits of both plants. They demand and respond to high fertility and fairly close grazing and have a long growing period. Stimulated with appropriate fertilisers full utilisation is readily obtainable . by controlled grazing and the conservation of surplus summer production as silage. Our immediate interest is to speed up the adoption of the practices leading to full production and utilisation of perennial ryegrass-white clover pastures over as wide an area of dairying grassland as possible.

As grassland workers we are by no means satisfied that the perennial ryegrass-white clover pasture is by any means the ideal for dairy cow production. We would like higher winter and early spring production and we would like to avoid the necessity for heavy silage conservation for summer feeding. In short what we desire are pasture combinations that will produce seasonal feed corresponding to the seasonal requirements of the dairy cow and at the same time produce as economically as much as and preferably more than perennial ryegrass-white clover pastures.. Hence our perpetual search for special-purpose pastures and grazing-management methods appropriate. for their permanence and full production. It is I think appropriate that we have viewed to-day a farm where many of the ideas of grassland workers have been put into practice. We have seen the use made of prairie grass and short-rotation ryegrass for winter feeding, the contributions of cocksfoot and timothy for summer feeding, and the place of supplementary fodder crops in the pasture-management and feeding programme. In short, we have seen what skilful management has done in extending the seasonal provision of feed for dairy cow requirements. We naturally ask ourselves how far Mr Hunger's practices can 
be extended in general dairy farm practice, for we must not let our enthusiasm outpace our knowledge.

The basic advantage of the perennial ryegrass method is that the rules for high production are fairly simple ; raise soil fertility by appropriate topdressing and aim for as full utilisation as possible. Although full utilisation requires carefully controlled grazing and silage making, production is not usually unduly reduced by minor defections from good management. The position is somewhat different with what may be termed special purpose pastures. They require more care in management and will not stand hard winter grazing; hence the need for adequate reserves of winter feed. Indeed, 'it is doubtful if the full system of special purpose pastures can be worked without some annual cropping.

My suggestions for grassland research and discussion by grassland workers for increased feed production on dairy farms are: first, work for the general adoption of a perennial ryegrass-white clover, fullutilisation programme, and secondly, parallel this with careful investigation of the role and methods of management of special-purpose pastures and spread seasonal production. I feel that in the past we have talked too much and done too little about special-purpose pastures. We have seen illustrations of their use today. Let us, as it were, take the method apart and examine the details. What, for instance, is the production of prairie-grass pastures and what managerial methods are necessary for their maintenance. Let the research worker first work on the parts and measure production and then seek examples such as we have seen today and put the pieces together and see how they are reflected in farm management and production. 